\title{
THE MECHANISM FOR IDENTIFYING AND RESPONDING TO REAL AND POTENTIAL THREATS IN THE SYSTEM OF ENSURING ECONOMIC SECURITY IN INNOVATION AND INVESTMENT POLICY
}

\author{
Anna V. Shokhnekh ${ }^{1, *}$, Yuliya V. Melnikova ${ }^{1}$, Tatiana A. Dugina ${ }^{2}$, Alexander V. Nemchenko ${ }^{2}$, and Alexey A. Mironov ${ }^{3}$ \\ ${ }^{1}$ Volgograd State Socio-Pedagogical University, Volgograd, Russia \\ ${ }^{2}$ Volgograd State Agrarian University, Volgograd, Russia \\ ${ }^{3}$ Volga State University of Technology, Russia, Yoshkar-Ola
}

\begin{abstract}
Forming the concept of the essence of economic security of innovation and investment policy makes it possible to use it as the foundation for making managerial decisions aimed at enhancing such attributes of sustainability as competitiveness, paying capacity, enterprise, and adaptability. The mechanism for identifying and responding to real and potential threats in the system of ensuring economic security in the innovation and investment policy will make it possible to carry out a set of interrelated measures of an economic, legal, organizational nature: to formulate and apply a system of measures to predict risks; to prevent impacts leading to the weakening of internal and external threats to vital cycles in innovation and investment policy at the macro, meso and micro levels; provide a sense of security for the management and personnel, as well as capital involved in innovation and investment policy. The article explores the areas of economic security based on the "Eulerian circles", reflecting different levels of security.
\end{abstract}

\section{Introduction}

The methodology for ensuring economic security of innovation and investment policy, which includes a mechanism, tools and indicators, and indicators, should be determined by characteristics such as technology, production capabilities, human resources, financial security, prospects for market position, functional features.

The system of real and potential threats is not static, since threats can appear and disappear, increase and decrease or exist in a hidden form for a long time.

The security threat is associated with the loss of stability and the transition to turbulence of innovation and investment policies at the meso- and micro level. In the period of turbulence, intensive changes occur in the internal and external environment of the business, and a slowdown in growth rates might take place. During this time "weaknesses" that need protection are identified. At the same time, new opportunities, that should be taken advantage of, are also indicated. Knowing the conditions for the emergence of a turbulent environment can contribute to creating a system of protection against threats to economic security, "which should have protective circuits of the financial, distributing and property systems." Therefore, it is necessary to develop general rules of the game, which should be understood and applied for the conscious management of the economic security system [Glazyev S. Yu .; Makarova
N. N., 2012]. It is important to develop such a system for ensuring economic security of innovation and investment policy, which is based on organizational flexibility and planning, taking into account unforeseen circumstances.

\section{Discussion}

The mechanism for detecting and responding to real and potential threats is based on the development of certain scenarios that contain reflections on possible events that may occur, which will provide resistance to turbulent flow. In each scenario, there must be complied probable situations of the future development of the innovation and investment policy of the agricultural producer and its structures, its correlation with other systems. The optimal indicators of ensuring economic security are determined under various combinations of factors and external impact conditions.

The development scenarios of a possible determined turbulent environment consist in the following hypothesis:

- the laws of possible perturbations of the borderline contour are deterministic;

- the stochastic features of the turbulent environment of innovation and investment policy are generated by external disturbances, which are amplified by chaotic cycles.

If all instabilities of the borderline contour lead to a displacement into the internal medium, then the position

\footnotetext{
Corresponding author: $\underline{\text { shokhnekh } @ \text { yandex.ru }}$
} 
can remain mostly determinate even after the transition to turbulence is completed (i.e., absolute and global instabilities are not considered). The probability of implementing each of the scenarios of innovation and investment policy at the meso- and microlevels should be assessed using expert assessments. An analysis of innovation-investment policy scenarios at the meso- and microlevels allows us to evaluate the effectiveness and consistency of managerial decisions distributed in time and space. Drawing conclusions, the authors argue that the more the turbulence of innovation and investment policies increases at the meso- and microlevels, the more aggressive should be the reaction of the economic security system to neutralize or reduce the intensity of specific impacts [Makarova N.N., 2019; Kunitsa M.N., 2017; Rogachev A.F., 2015].

\section{Materials and methods}

To test the proposed hypothesis, a statistical analysis and synthesis of ontological approaches to innovation and investment policy are used. It is advisable to disclose the ontology of ensuring economic security in a cyclic transformation using behavioral economics and neuroeconomics. However, currently economic security is interpreted both at the country level and at the level of an economic entity.

At the macro level, economic security is represented as a state of the economic system, which is characterized by: 1) resistance to perceived threats and the ability to identify development paths to protect national interests; 2) a high level of security of production and social relations of a business entity from the negative influence of internal and external factors, which indicates the ability to increase the level of well-being of the people and the development of the economy overall [Ganin O. B., 2015; Melnikova Yu.V., 2020; Shokhnekh A.V., 2019; Hol-cheva I. A., 2019].

It seems as an adequate point of view to argues about the need for state protection of economic entities as a high level of public relations in a state of law, guaranteeing the stability of the areas of economic reproduction regardless of internal or external contradictions [Bykov, B. A., 2017].

The authors share the point of view, that protection from threats involving targeted financing to minimize risks determines the level of economic security that ensures the sustainable development of the economic system with a minimum probability of undesirable changes, as: 1) it is constantly maintained the process of eliminating and preventing possible negative impacts on the economic interests of the subject; 2) the protection of human and intellectual potential, information, technology and profit level is ensured; 3) goals and objectives are set, and they have an internal controlled structure; 4) scenarios of the organization's activity routes under the influence of environmental factors are determined [Melnikova Yu.V., 2019].

\section{Research part}

Currently, the institute of economic security is being actively formed, which is being built in conjunction with the science, which involves the identification of the basic principles and discloses the ontology of ensuring economic security in a cyclic transformation:

1) the institute of economic security is a scientific and methodological sphere in which the doctrine of theories is written by civil society for its social needs and needs from a protection perspective;

2) the institute of economic security represents the scientific and applied sphere, which is used throughout the life of society;

3 ) the institute of economic security is a subject to theoretical and methodological components formed by nature, which determines the direction of the laws of life and being;

4) the institute for economic security identifies social risks, which affect the economic system [Kaurova N. N., 2012; Shokhnekh A. V., 2014].

5) the institute of economic security explores, identifies and neutralizes the impact of the virtual economy, which is based on: ignoring the world's tough security mechanisms of property, liabilities, financial income; lack of valuation standards; excess of the money supply over tangible, intangible equivalents, valued at unreasonable value;

6) the institute for economic security is formed on evaluating principles of the analytical design [Schumpeter Ya. A., 1982]; an assessment is an analysis of qualitative and quantitative attributes that consumers need to satisfy their desires (an assessment can include both the costly component of a resource and consumer demand; an assessment is a physical measure that obeys the theoretical laws of physics);

7) the institute of economic security is formed on the principle of control, which identifies inaccurate estimates in the value of the consumer product, plays a crucial role in the imbalance of many conceptual areas of economic science;

8 ) the institute of economic security is formed on the principle of coordination, which makes proposals for adjustments to the normative and creative activities of society on the basis of identified distortions and inaccurate assessments.

Such an institutional approach is becoming a key one and is complicated by the need to integrate agricultural organizations into a digital communication field as a condition for unlocking potential in rapidly developing technological processes.

But fast integration into the digital field does not occur in Russia. Given the huge size and diversity of Russian territories, as well as the diversity of traditions that determine the needs of the population, it is advisable to form a digital information and communication field as a state initiative in promoting innovation. State initiative in sectors of the economy (especially in the business environment) is accompanied by risks in promoting innovation. That is why the issues of ensuring economic security in the digital economy are becoming especially relevant [Melnikova Yu.V., 2019]. 


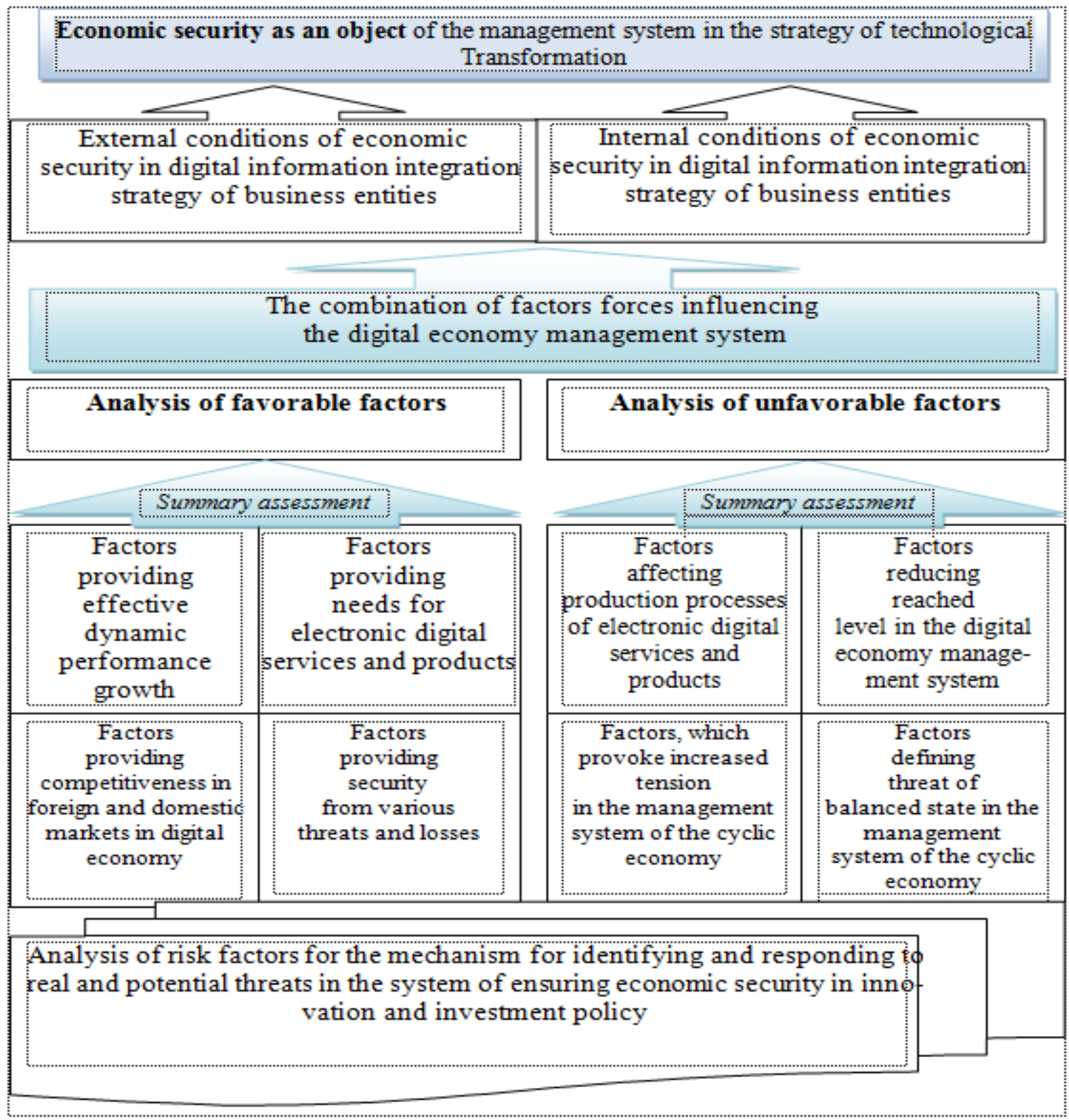

Fig. 1. Analysis of risk factors for the mechanism of identifying and responding to real and potential threats in the system of ensuring economic security in innovation and investment policy (Source: compiled by the authors [Shokhnekh A.V., 2018; Melnikova Yu.V., 2019; Gerashchenkova T.M., 2014; Gladysheva A.L., 2014]).

Since the mid-twentieth century, basic economic theory has been developing in separate directions, taking into account the peculiarities of the property of capitalism in the digital economy system from the perspective of economic activity becoming virtual, which was noted by modern and classic economists. But highlighted features of the digital economy did not have sufficient elaboration and corresponding attention from the authorities.

Provisions of a theoretical and methodological nature secured the basis for the effective operation of the production economy, distribution, consumption as an economy of the real sector. But technological digitalization of the second half of the twentieth century predetermined the dominant role of service industries and intangible production in the new "virtual economy". At present, when the intangible sectors of an innovative product have exceeded the efficiency of the real sector, crises are defined in the economy that prevent the development of new areas of the digital economy [Shokhnekh A.V., 2018; Makarova N.N., 2019; Gerashchenkova T.M., 2014; Gladysheva A. L., 2014].

Therefore, in the mechanism for identifying and responding to real and potential threats in the system of ensuring economic security in the innovation and investment policy it is necessary to analyze the conditions for implementing the information integration strategy of electronic-digital management. They form an 
integrated complex organization, segmented into external and internal elements of

impact (factors).

The functional elements of the mechanism for identifying and responding to real and potential threats in the system of ensuring economic security in innovation and investment policy include:

1) identifying information about the critical points of economic security of the information integration strategy of electronic-digital management of agricultural organizations;

2) forming information on the mechanisms of economic security in the strategy of information integration of agricultural organizations in the electronic digital field;

3) forming information on economic security mechanisms that neutralize fraud, cybercrime, corruption, provocation of entrepreneurs' victim behavior of agricultural organizations in the Internet space and other digital technologies;

4) forming information about errors in the system of economic security at the micro level in the digital economy.

The mechanism for ensuring strategic economic security of innovation and investment policies of agricultural organizations is formed under the influence of the following factors:

1) favorable: stimulate the effective dynamic growth of indicators in the digital economy; provide the needs of the Internet users with space and electronic digital techniques and technologies; increase competitiveness in foreign markets; provide protection against various threats and losses;

2) unfavorable: stagnate the production processes of electronic-digital services and products; reduce the achieved level, which provokes tension in the digital economy management system in the strategy of information integration of electronic-digital economy; determine the threat to a balanced existence (Figure 1).

The main threat to the economic security of agricultural organizations at the cognitive level of the Internet users and other digital communications is a low level of critical analysis capabilities, which is determined by an unqualified faith: trust in the applied search engines, clip operations, trans due to the constant Internet surfing, hemophilia and etc. New business opportunities at the micro level are being formed on the new generation consumers' way of thinking (high school and university students) who are "born in networks" and are significantly deformed.

An important development indicator of the digital economy management system and a problem for the mechanism of identifying and responding to real and potential threats in the system of ensuring economic security in the innovation and investment policy is the accessibility of the Internet space, since payments, orders, communication with authorities, society and business are not possible without the Internet.

According to current conditions, it is essential to build not only risk mitigation mechanisms, but also identification of opportunities, the loss of which will be equated for agricultural organizations with: loss of competitiveness; the formation of distorted data on consumer demand, erroneous projects of market offers, loss of stability of pricing policy.

There should be mentioned the concept of I. Ansoff, who made a significant contribution to the process of forming economic application of turbulence [Prigozhin I., 1985; Melnikova Yu.V.]. Such qualitative effects as the state of expansion and repetition, change, discontinuity, and unexpectedness are reflected in the description of the model of the external environment of the company.

These level characteristics describe a different combination of qualitative indicators of variability and possibility of predictability of external events. Each qualitative level inherent in the conditions of turbulence of the external environment can suggest the optimal model of market behavior of an economic entity, which is important in the system of ensuring economic security of an economic entity. It is clear that the analysis of environmental turbulence conditions for the frequency and types of changes for the business entity will give information flows about the phenomenon and processes occurring in it to justify decisions made in the system of ensuring economic security.

\section{Final part}

According to the authors, the turbulent state is inherent in all economic systems that are affected by external factors that are manifested in the instability of the national economy, reducing the dynamic growth of economic entities. That is why, currently research has been intensified on the possibility of ensuring the economic security of business entities under turbulence, which is one of the directions in modeling the optimal mechanisms for eliminating threats.

A substantial study of ensuring economic security will allow us to build an optimal model of the variant choice of operating long-term relatively constant factors (fi), trending (ft), stochastic (fs), fluctuating (fk).

Studies show that the methods of the science in ensuring economic security can be defined in a conditional model built with fundamental laws in mind. The result of such a quantity can be marked by SESvv.

In the model of ensuring strategic economic security, it is advisable to identify four factors that accumulate or increase the level of economic security. Such factors can have both positive effects that provide a level of economic security, and negative ones that lead to insolvency.

For simplicity and consistency of calculations, it is proposed to identify four areas to which factors can be attributed:

1) fi - relatively constant factors;

2) $\mathrm{ft}$ - trend factors;

3) fs - stochastic factors;

4) fk - fluctuating factors.

Obviously, the factors of providing economic security (Fpes) - will be presented with the "+" sign, and with the "-" sign will be reflected the factors of insolvency of economic security (-Fies) (Table 1). 
Table 1. Classification of factors of the economic security.

\begin{tabular}{|l|l|}
\hline \multicolumn{1}{|c|}{ Groups of factors providing economic security (Fpes) } & Groups of factors of insolvency of economic security (-Fies)) \\
\hline $\mathrm{fc}$ - relatively constant factors & -fc - relatively constant factors \\
\hline $\mathrm{ft}$ - trend factors & -ft - trend factors \\
\hline $\mathrm{fs}$ - stochastic factors & -fs - stochastic factors \\
\hline $\mathrm{ff}$ - fluctuating factors & -ff - fluctuating factors \\
\hline
\end{tabular}

Identified factors affecting economic security are ranked in four areas. In order to ensure economic security, there are factors selected which enhance economic security, and then factors that reduce the level of economic security.

Factors that reduce the level of economic security, just like factors that enhance economic security, can fall into 2,3 or 4 areas at the same time.

To model the mechanism for identifying and responding to real and potential threats in the system of ensuring economic security in the innovation and investment policy, the use of "Eulerian circles" is proposed. Such diagrams were first introduced by Leonard Euler in his work. Eulerian circles provide visibility in the process of solving complex problems, making the answers obvious

Figure 2 presents the factors and reflects the area of the most enhanced level of economic security.

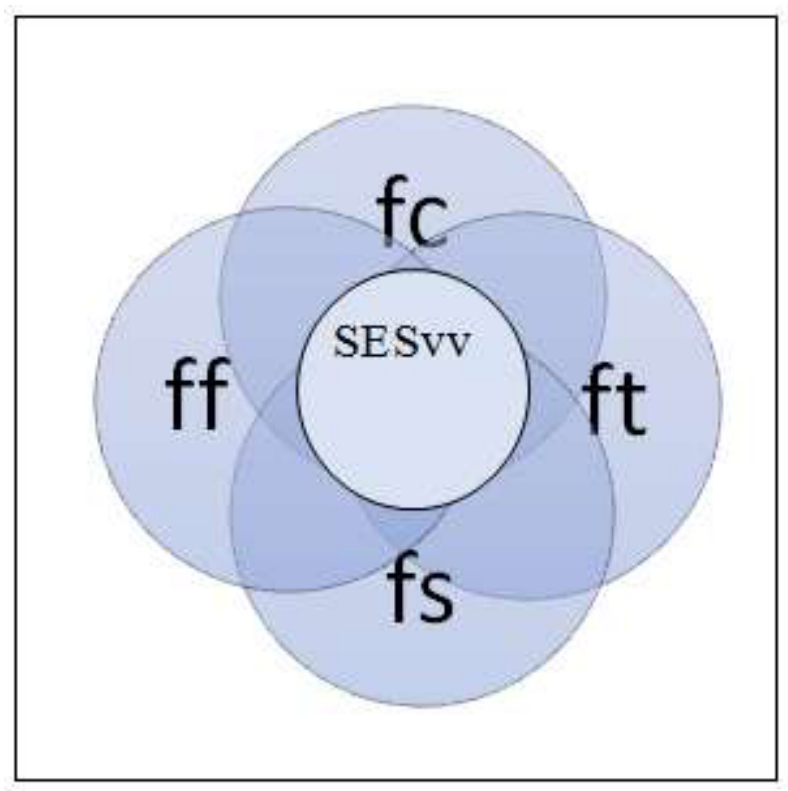

Fig. 2. The area of economic security based on the "Eulerian circles", reflecting a fairly high level (Source: compiled by the authors [Shokhnekh A.V., 2018; Melnikova Yu.V., 2019; Shokhnekh A.V., 2019; Shokhnekh A.V., 2020]).

An analysis of the level of economic security should be carried out on the basis of a judgment on the intersection of factor areas of ensuring economic security. It means that as there are more overlapping areas and often repeated factors in different groups, as higher the level of economic security is.

Such four or three-fold intersection indicates enhanced control over the level of ensuring economic security in the economic entity.
A visual express analysis of the level of ensuring economic security based on the Eulerian circles is presented in Figure 3.

Carrying out the analysis, it is necessary to understand that the looser the circles look, the lower the level of economic security is. And vice versa, the more overlapping circles take place, the higher the level of economic security is.

According to the same principle, it is advisable to conduct a visual express analysis of the level of incoherence of economic security. It is important to analyze the presence of factors that threaten the provision of economic security or reduce its level. All factors are reflected in the chart with a "-" sign. The level of economic security will also be reflected with a minus sign and read as the level of non-co-operation (SESvv).

Figure 4 presents a visual express analysis of the level of insolvency of economic security.

It is important to note that raising interest rates on loans significantly affects the intensity of investment policy in the field of agriculture in the Russian regions. It is quite obvious that while the problem of import substitution is not solved in terms of resources, there can be no guaranteed food security of the state [Melnikova Yu.V., 2019; Shokhnekh A.V., 2019; Shokhnekh A.V., 2020]. It should be taken into the account, that this is a complex not so much of sectoral and agrarian difficulties as the intersystem, intersectoral and macroeconomic problem of the interaction of managerial and financial structures.

An integral segment of the mechanism for ensuring economic security in innovation and investment policy is insurance. Insurance allows you to compensate for losses. Firstly, it is also one of the most stable sources at the time of the risk of agricultural resources loss. Secondly, it removes anxiety, and, therefore, stimulates innovation and investment activity. In this context, the importance of insurance is considered in order to provide the economic security of users of insurance market services. From the perspective of ensuring the protection of the economic safety of insurance organizations, it is vital to include the risk component in the structure of the insurance tariff.

The insurance service for the protection of innovation and investment activities of agricultural organizations is a monetary indemnity for the insured upon the occurrence of an insured event stipulated by the insurance contract. In the economic concept, the insurance service (which is sold on a paid basis) means the transfer of risk from the insured to the insurance organization in correlation with the occurrence of events specified in the insurance contract. 


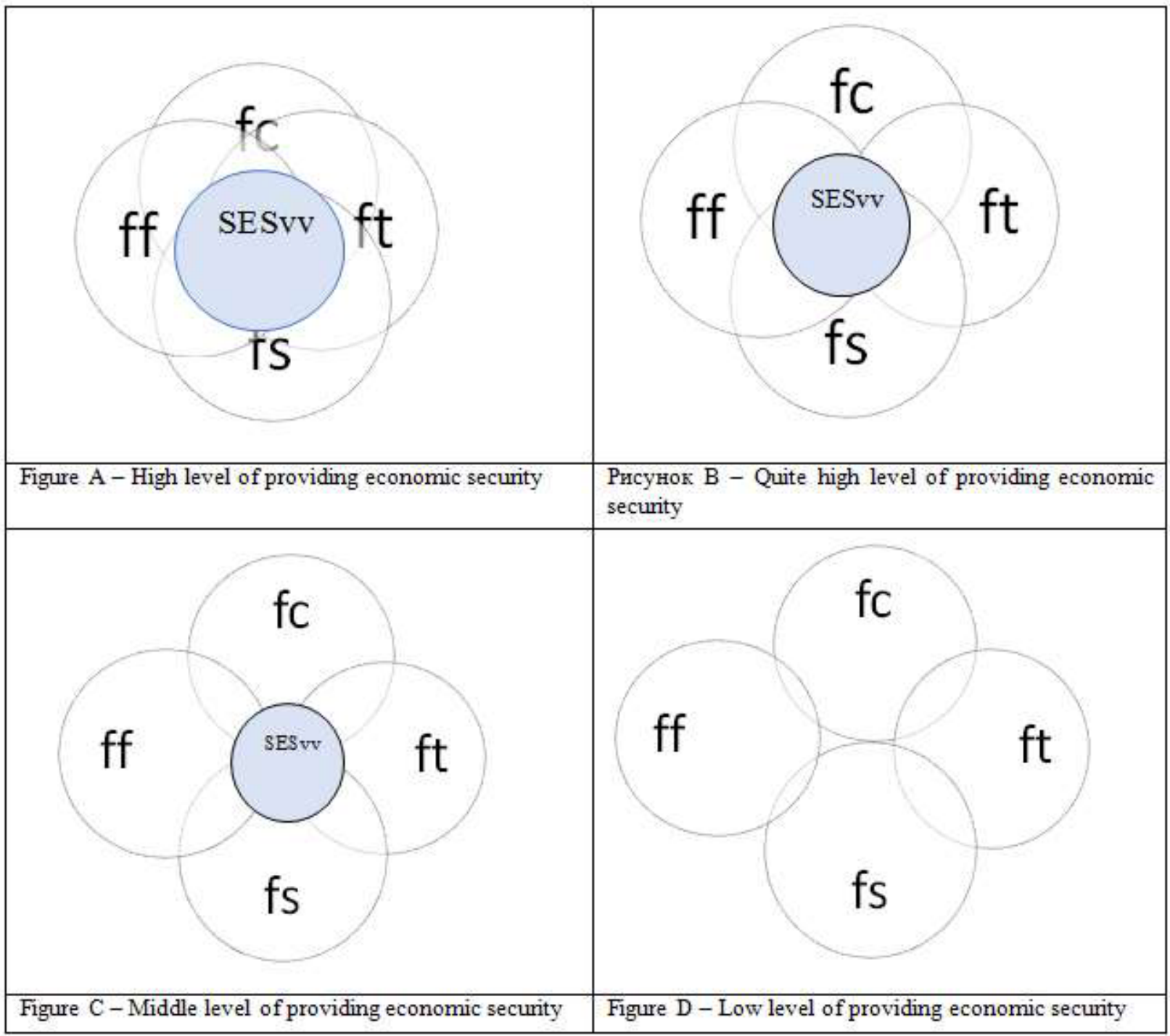

Fig. 3. Visual express analysis of the level of economic security based on "Eulerian circles" (Source: compiled by the authors [Shokhnekh A.V., 2018; Melnikova Yu.V., 2019; Shokhnekh A.V., 2019; Shokhnekh A.V., 2020]).

The life cycle of insurance services differs from other types of goods. Firstly, the service life cycle is much longer. Since the company can sell insurance poles for a long time - a year, two or three years, five years, decades (while for most products with higher demand, this is impossible). Secondly, the initial cost of designing and introducing a service to the insurance market is much less than for mass consumer products.

There exist amendments to the Federal Law "On State Support in the Field of Agricultural Insurance and on Amendments to the Federal Law" On the Development of Agriculture", which are in force since 2016.

Consequently, forming of an insurance policy of innovation and investment activities of agricultural organizations is aimed at ensuring economic and food security through the development of insurance services and state support in the structure of adaptive reform. This approach not only enhances the food and economic security of the state, but also ensures the development and promotion of insurance products in innovative investment activities of agricultural organizations [Melnikova Yu.V., 2019; Shokhnekh A.V., 2019; Shokhnekh A.V., 2020].

Current trends determine the need for a compensating mechanism based on insurance services in the model of ensuring strategic economic security. This promotion is especially convenient and relevant through electronic communication channels. Promotion of insurance services through the network contributes not only to increasing the coverage of agricultural organizations interested in insurance, but also to strengthening the positions of insurers in terms of economic safety. Recently, through the network, it is possible to regulate insured events in case of minor damage, as well as systematically keep records of insurers and information about them remotely. 


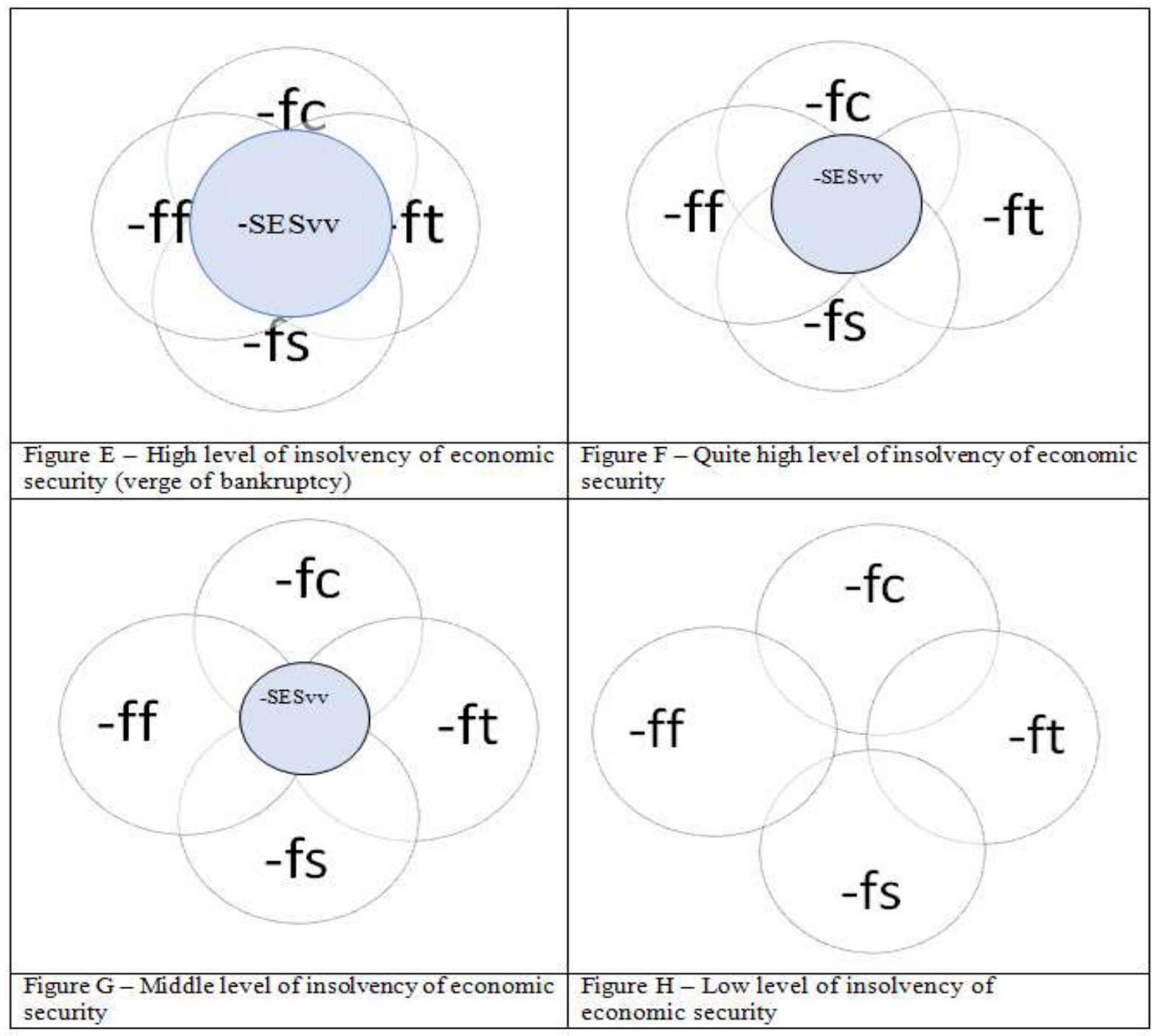

Fig. 4. Visual express analysis of the level of insolvency of economic security based on "Eulerian circles" (Source: compiled by the authors [Shokhnekh A.V., 2018; Melnikova Yu.V., 2019; Shokhnekh A.V., 2019; Shokhnekh A.V., 2020]).

\section{Conclusion}

In the conclusion of the research, it's determined that there is an expediency of strategic management in ensuring economic security, which is an important, innovative way to provide successful activity. The current state of the agro-industrial complex is being substantially transformed under the influence of the sanctions policy in the field of food restrictions for our country. These changes over the past five years have been acting simultaneously in opposite directions. On the one hand, Russian sanctions are expanding opportunities for domestic agricultural producers, which is already reflected in the growth in output of food industry goods. On the other hand, anti-Russian sanctions lead to higher interest rates on loans for Russian producers. The increase of the interest rates on loans significantly affects the intensity of investment policy in the field of agriculture in Russian regions. It is quite obvious that food security of the state cannot be guaranteed without solving the problem of import substitution in terms of resources, It should be considered that it is a complex not so much of sectoral and agrarian difficulties as the intersystem, intersectoral and macroeconomic problem of the interaction of managerial and financial structures.

\section{Acknowledgements}

The reported study was funded by the Russian Foundation for Basic Research grant No. 19-010-00985 A. "Development of innovative and investment policy as a concept of strategic economic security of agricultural organizations in the conditions of the modern technological transformation".

\section{References}

1. S.Yu. Glazyev, On the strategy of modernization and development of the Russian economy in the conditions of global depression Electronic resource.. Available at: http://www.glazev.ru. 
2. N.N. Makarova, A.V. Shokhneh, Turbulent approach to the system of ensuring economic security of economic entities, Audit and financial analysis, 6, 397-400 (2012).

3. M.N. Kunitsa, Features of the modern transformation of the agricultural complex of the Bryansk region, Bulletin of agrarian science 6,69 , 124-131 (2017).

4. A.F. Rogachev, A.V. Shokhnekh, Genesis of mathematical models of econophysics as a path to food security, Audit and financial analysis, 1, 410413 (2015).

5. O.B. Ganin, I.O. Ganin, Economic security of the municipality: Genesis, essence and content of the concept, ARS ADMINISTRANDI, 61-84 (2015).

6. Yu.V. Melnikova, A.V. Shokhnekh, Forming the policy of insurance of innovative and investment activities of agricultural organizations as a conceptstrategy of provision of economic and food security, Lecture Notes in Networks and Systems 87, 809-816 (2020).

7. A.V. Shokhnekh, O.A. Mironova, L.R. Moiseeva, L.Y. Yakovleva, A.K. Evstafieva, A.V. Shokhnekh, Provision of innovational and economic security of small business in the internet space of cybereconomy on the platform of cognitive assistants of artificial intelligence, Studies in Computational Intelligence, 826, 1023-1029 (2019).

8. I.A. Holcheva, A.E. Kisova, Main approaches to the study of the concepts of "economic security" and "economic security of the state", Science diary 5, 29, 96 (2019).

9. S.A. Kasperovich, E.A. Derbinskogo, Evolution of the concept of "economic security, The works of BGTU, Series 5, Economics and management 5, 2017, no. 1, Pp. 214-218 (2017).

10. I.A. Ganieva, Digital transformation of Russian agriculture: consolidation of the state and agricultural business, Achievements of science and technology of the agro-industrial complex 33, 4, 57 (2019)

11. B.A. Bykov, On a possible alternative approach to the definition of "economic security", Man: crime and punishment 25, 1, 32-37 (2017).

12. Yu.V. Melnikova, ed. A.V. Shokhnekh, Genesis and ontology of innovation and investment policy as a concept of economic security of agricultural organizations in the conditions of digital transformation: monograph (Ufa, 170, 2019).

13. N.N. Kaurova, Banks and microfinance organizations: who will be the first to help small businesses Electronic resource., 4, 8-16 (2012). Available at: the legal system "Consultant".

14. A.V. Shokhnekh, L.A. Sizeneva, E.S. Vasiliev, V.V. Chudnova, The role of regional financial policy in ensuring economic security of business development and integration in Russia, Audit and financial analysis, 1, 398-401 (2014).

15. A.V. Shokhnekh, V.S. Telyatnikova, L.I. Nasonova, Digital economy: theory and methodology of integration of subjects in the electronic digital pre-consumer field: monograph (Ufa: AETERNA, 170, 2018).

16. N.N. Makarova, A.V. Shokhnekh, Synergetic Approach to The Formation of The Innovative Investment Policy of Enterprises in The AgroIndustrial Complex: Goal-Setting and Forecasting, International Journal of Recent Technology and Engineering (IJRTE) 8, 1, 2688-2690 (2019).

17. T.M. Gerashchenkova, About factors of ensuring the effectiveness of innovation-investment processes, Bulletin of Novgorod State University of Yaroslav the Wise, 76, 77-82 (2014).

18. A.L. Gladysheva, O.N. Gorbunova, I.F. Chepurova, Human resources and innovations as the most important components of a company's competitive advantages, Social and economic phenomenon and processes 9, 11, 34-38 (2014).

19. I. Prigozhin, From existing to emerging (Moscow: Nauka, 328, 1985).

20. Y.V. Melnikova, A.V. Shokhnekh, Forming the policy of insurance of innovative and investment activities of agricultural organizations as a conceptstrategy of provision of economic and food security, Lecture Notes in Networks and Systems 87, 809-816 (2020).

21. T.A. Shcherbina, Digital transformation of agriculture of the Russian Federation: experience and prospects, Russia: trends and development prospects, 450-453 (2019).

22. A.V. Shokhnekh, Y.V. Melnikova, T.M. Gamayunova, The investment concept strategy of development of innovative activities of agricultural organizations in the conditions of techno-economic modernization, Lecture Notes in Networks and Systems 87, 796-808 (2020).

23. A.R. Saifetdinov, M.E. Trubilin, G.G. Grateful, P.V. Puzeychuk, Features of innovation and investment transformation of enterprises and sectors of the agro-industrial complex, Colloquiumjournal 11-9, 22, 83-87 (2018).

24. T.I. Grudkina, T.S. Khomaiko, A.O. Lelyakin, Increasing the efficiency of crop production and creating of competitive advantages by agricultural business entities, Concept, 6, 1-9 (2014).

25. V.M. Taroyan, Innovations in Human Resource Management, Bulletin of the St. Petersburg State University of Economics 2, 92, 120-122 (2015).

26. G.A. Dryomina, The use of technological innovation in the reengineering of banking (Omsk Scientific Herald, 104-107, 2012).

27. A.F. Rogachev, E.V. Melikhova, A.V. Shokhnekh, Monitoring and economic \& mathematical modeling of manufacture and consumption of agricultural products as a tool of food security management, Espacios 39, 1, 1 (2018). 